\title{
What will the horrible year of 2020 bring to the future of ageing research?
}

\author{
Susanne Iwarsson ${ }^{2} \cdot$ Marja J. Aartsen $^{1} \cdot$ Morten Wahrendorf $^{3} \cdot$ Matthias Kliegel $^{4}$
}

Accepted: 23 January 2021 / Published online: 22 February 2021

(c) The Author(s), under exclusive licence to Springer Nature B.V. part of Springer Nature 2021

The year 2020 was very special, qualifying without doubt as an annus horribilis. For example, the cover page of the Time Magazine had "the Worst Year Ever"-crossed over in red-as theme of their December 2020 issue (Waxman 2020). First and foremost, this refers to the COVID-19 pandemic, but also to numerous events that shaped the year as an extraordinary one.

No matter their disciplines and research interests, most researchers around the world experience a large impact of the pandemic on their work. Not the least for those of us doing research on ageing, COVID-19 has put the light on the grand challenges and opportunities of population ageing in a multifaceted manner. With older people-rightly or wrongly defined as a risk group early on-the pandemic has uncovered deficits in healthcare services for older people, risks for social isolation, challenges regarding digital literacy and technology, etc. There are also positive examples showing that older people rapidly learned to make use of digital technology at a higher pace than ever before (Andersson et al. 2020), speaking to their agency to adapt to new situations. Such complex developments stimulate researchers around the world to generate bold research ideas and projects, crucial for the development of novel scientific lines of inquiry and of new knowledge for the years ahead. Thus, despite the negative consequences of the pandemic, the interest and need for ageing research is growing and stronger than ever before.

Researchers on ageing acted on this situation from the beginning, and the European Journal of Ageing responded with a call for papers for a special section on the COVID-19

Marja J. Aartsen

maraar@oslomet.no

\footnotetext{
NOVA Norwegian Social Research, Oslo, Norway

Lund University, Lund, Sweden

Heinrich-Heine University, Düsseldorf, Germany

4 Université de Genève, Geneva, Switzerland
}

pandemic. The team of Editors-in-Chief invited Giovanni Lamura and Clemens Tesch-Römer as Guest Editors. Topics of interest could include, but were not limited to, increasing inequalities in the impact of the disease, consequences of quarantine and social distancing for older people, behavioural consequences of fear, resilience in the face of Corona, ICT communication and well-being, increasing ageism, etc. The deadline for submissions to the Consequences of the Corona Pandemic in Later Life special section was September 2020. We received more than 50 interesting abstracts and invited the twelve most promising of those to submit a full paper. The special section will be published later this year.

The pandemic has further lead to many initiatives aiming to highlight and act upon challenges and opportunities that are specific for the ageing population. For example, the latest United Nation (UN) Network on Ageing Newsletter listed numerous initiatives, such as the Impact of COVID-19 on Older Persons policy brief, which is intended to guide countries to tackle economic and social dimensions of the pandemic, with older people as a prioritized group. The objective of the checklist provided in the policy brief is to provide guidance to evaluate whether socio-economic impact actions apply a human rights-based approach, to ensure that older people will not be left behind. The implementation of the Madrid International Plan of Action on Ageing is getting closer, and recently the UN's General Assembly declared 2021-2030 the Decade of Healthy Ageing. Governments, international and regional organizations, civil society, the private sector, academia, and the media all over the world are encouraged to support the goals set for this decade. The Editors-in-Chief of the European Journal of Ageing will actively work in this direction. We foresee that during the years to come we will receive many submissions relating to the COVID-19 pandemic from a diversity of perspectives, and we are looking forward to publishing landmark papers in the spirit of the Decade of Healthy Ageing.

While 2020 can be labelled a horrible year, the pandemic situation has highlighted the situation of older people and 
population ageing as core areas that warrant increased attention, not the least in terms of research initiatives. Thus, progressive development based on novel knowledge on hitherto underprioritized areas might be a positive outcome in the longer term.

As journal Editors we have experienced major challenges because of the pandemic, most of all related to the strained work situations of colleagues being invited as reviewers for the journal. This is not specific for the European Journal of Ageing but universal in the scientific publishing sector. We would like to thank the Springer office for foresighted support and strategic action to counteract negative consequences, but we are nevertheless experiencing a situation with delayed review processes. We are very grateful to our colleagues who, despite strained work situations and sometimes repeated queries and reminders from us, have been engaged as reviewers during the year.

We are also very grateful to all the authors who produced interesting research results and decided to submit their manuscripts to the European Journal of Ageing, demonstrating positive endurance and acceptance of the delayed review processes. During 2020, in all 49 papers were published, showcasing the multi- and interdisciplinary scope of the journal. The papers demonstrate an impressive range of different research designs and methodologies and include theoretical, methodological as well as empirical contributions. Examples published during 2020 are a theoretical paper on Weber's concepts of instrumental and value rationality $(\mathrm{Xu}$ et al. 2020) and an informative methodological paper on dropout due to death among oldest old people in longitudinal studies (Raitanen et al. 2020). Very timely in the light of the pandemic, Fischl et al. (2020) concluded in a qualitative study that co-creating digital services and facilitating satisfactory use could support social participation through activities that older people find relevant and might enable them to age in place. Another example is a large-scale study based on the Survey of Health, Ageing and Retirement (SHARE), concluding that the gender health gap within ageing populations cannot be regarded as a universal finding as it tends to widen, narrow, or even reverse with age depending on indicator and country (Schmitz and Lazarevič 2020). Moreover, two issues included a special section, where the first was on Sexual Well-being in Older Adults, with guest editors Bente Træen and Feliciano Villard (Træen and Villar 2020). The second concentrated on Views on Ageing, with Verena Klusmann and Anna Kornadt as guest editors (Klusmann and Kornadt 2020). We would like to thank the guest editors for their commitment and fine contributions to the journal.

Despite the aforementioned challenges and thanks to the interest and encouragement of colleagues around the world, we are pleased to announce that there has been a consistent and steady growth of the number of new submissions. The turn-around time for submissions to the journal has improved from 315 days in 2018 to 265 days in 2019. This is highly relevant as the previous year highlighted the importance of a fast dissemination of current findings. The acceptance rate for 2019 was $18 \%$. The overall satisfaction rate of the journal is increasing, and we are happy that authors increasingly perceive the editorial advice and management of the journal as excellent. Moreover, the 5-year impact factor is gradually improving and is currently 2.539 . As approximately $80 \%$ of the published papers originated from Europe, with the ambition to increase the international interest and outreach we would like to take the opportunity to encourage researchers from other continents to submit their manuscripts to the journal.

Finally, some words from the new combination of Editors-in-Chief. From January 2021, there was a change in the team of Editors-in-Chief. Susanne Iwarsson has been the health sciences and public health editor for a 3-year term and has decided that she will not renew her contract. We are happy to announce that Morten Wahrendorf, who has served as an Associate Editor since 2018, has transitioned to the role as Editor-in-Chief. As he is already well acquainted with the journal and the editorial tasks, we are confident that we will experience a smooth transition, and we warmly welcome him as one of the three Editors-in-Chief. From this place, we would like to thank Susanne Iwarsson for all the work done to the journal. She has been vital in ensuring that the journal maintains its high standards, and we are very grateful for the time and effort she has invested in the journal. She will resume her role as a member of the Editorial Board and thus continue her longstanding support of the journal, which is highly appreciated.

Taken together, 2020 was a difficult but stimulating year for research on ageing. Numerous new research questions have been uncovered, and the importance of hitherto underprioritized areas has been underlined. As journal editors, we hope that manuscripts that meet these emerging research needs will be submitted to the European Journal of Ageing-papers that develop new and extend existing scientific lines of inquiry. Whatever happens during 2021, we look forward to another year ahead and are confident that the European Journal of Ageing will offer a platform for the dissemination and discussion of high-quality research findings on ageing.

\section{References}

Andersson J, Bäck J, Ernbrandt T (2020) Svenskarna och internet 2020. Internetstiftelsen. https://svenskarnaochinternet.se/rapporter/svens karna-ochinternet-2020/fakta-om-svenskarna-och-internet-2020/. Accessed 28 Dec 2020

Fischl C, Lindelöf N, Lindgren H, Nilsson I (2020) Older adults' perceptions of contexts surrounding their social participation in a 
digitalized society - an exploration in rural communities in Northern Sweden. Eur J Age 17(3):281-290

Klusmann V, Kornadt AE (2020) Current directions in views on ageing. Eur J Age 17(4):383-386

Raitanen J, Stenholm S, Tiainen K, Jylhä M, Nevalainen J (2020) Longitudinal change in physical functioning and dropout due to death among the oldest old: a comparison of three methods of analysis. Eur J Age 17(3):207-216

Schmitz A, Lazarevič P (2020) The gender health gap in Europe's ageing societies: universal findings across countries and age groups? Eur J Age 17(4):509-520

Træen B, Villar F (2020) Sexual well-being is part of aging well. Eur J Age 17(2):135-138
Waxman OB (2020) The history behind TIME's use of a red ' $X$ ' on its cover. Time. https://time.com/5917946/time-magazine-red-Xcover/

Xu J, He L, Chen H (2020) Balancing instrumental rationality with value rationality: towards avoiding the pitfalls of the productivist ageing policy in the EU and the UK. Eur J Age 17(2):251-257

Publisher's Note Springer Nature remains neutral with regard to jurisdictional claims in published maps and institutional affiliations. 